\title{
Semantic Differential Analysis of the Soundscape in Urban Park
}

\author{
Xiu-Hua Song, Tae-Dong $\mathrm{Cho}^{1)^{*}}$, Yong-Ji Piao \\ College of Horticulture Science and Engineering, Shandong Agricultural University, Tai'an 271018, China \\ ${ }^{1)}$ Department of Environmental Landscape Architecture, Gangneung-Wonju National University, \\ Gangneung 210-320, Korea
}

(Manuscript received 4 July, 2012; revised 4 August, 2012; accepted 14 August, 2012)

\begin{abstract}
In this study, soundscape was analyzed through physical measurement and social surveys. The results showed that, soundscape components were related to functional partitions and tourist activities, at the same time influenced by ambient noise. The sound pressure levels showed daily regular changes. Semantic differential analysis showed that the evaluation of the soundscape in urban park was rather complicated. It was still possible to identify major factors including relaxation, spatiality and environment. The results provided theoretical basis for improving urban park soundscape, and called attention to this problem.
\end{abstract}

Key Words : Urban Park, Soundscape, Semantic differential analysis

\section{Introduction}

In the design of urban parks, the visual sense is always regarded as absolutely important while impressions from other senses, such as auditory, tactile, taste and smell sense are often neglected. Hearing behavior is not only the rudimentary sense for the acquisition of information, but is also one of the major means of catching aesthetic feelings of the environment. However the considerations of the sound element in the design of urban park are still inadequate. Furthermore the main aspects of the sound environment research are limited to noise prevention and control. With the urbanization, human beings are facing the problem of losing the amenity of natural, historical, cultural and social sound environment. So design should not only focus on the

*Corresponding author : Tae-Dong Cho, Department of Environmental Landscape Architecture, Gangneung-Wonju National University, Gangneung 210-320, Korea

Phone: +82-33-640-2358

E-mail: aroma058@hanmail.net prevention or control of undesirable elements, but also on creating more desirable elements actively.

In the end of 1960s, Canadian musician and composer Schafer (1977) first introduced the concept of sounscape, "the music in the environment", worthy of appreciation and memory from the perspective of aesthetics and culture angle in the narural and urban environment.Then soundscape spread quickly in the world. In the 21 st century, the study of soundscape gradually goes deeper, including the basic laws and properties of soundscape, methods exploration, as well as design and management of soundscape. The semantic differential method, developed by Osgood (1957) for identifying emotional meaning of words, has been extended to a large variety of concepts. Research proves that this method is a useful method to identify the most important factors in evaluating soundscape. For general urban environment sounds, the method has been used to analyze connotative and denotative meanings, and it has been suggested that evaluation, timber, power and temporal change are 
four essential factors (Zeitler and Hellbrück, 2001). Semantic differential method was used to evaluate sound elements of Saga Forest Park, and the park was zoned into three sound divisions by cluster analysis (Ge and Kazunori, 2004). Relaxation, communication, spatiality and dynamics are major factors that characterize the soundscape for both UK and Chinese situations (Kang and Zhang, 2010). The main objective of this study is to identify factors influencing the soundscape in urban parks through semantic differential method, and to provide the theoretical basis for soundscape evaluation and design.

\section{Materials and methods}

The study cases we selected are urban parks in Tai'an city Shandong province, Donghu park and Nanhu park. The criterion for this choice was based mainly on the fact that these parks are located in cores of urban density, surrounded by streets with heavy traffic and residential areas. The parks are typical urban park having a clear function partition, with complete elements like hill, water, vegetation and building. With the diversity of users the survey. And the results are universal.

In this research, a series of field studies were carried out. Stage one, on-site investigations were conducted twice in October 2011 in order to examine the general conditions of the park, especially the components and structure of soundscape. Five investigators walked around the parks and recorded the soundscape components, and measured sound pressure levels in terms of one-minute Leq at different time periods of weekdays. Six survey points in every park were chosen to measure the sound pressure with AWA6218 noise meter (Zhang and Ma, 2011; Chinese National Standard, 2008). All data were to be seved as a base for the following questionnaire surveys.

Stage two: Questionnaire surveys to visitors were conducted twice by two groups (with 3 students in each group) respectively and independently in March 2012. The questionnaire (Ge et al., 2006; Chen et al., 2009; Bani and Paulo, 2009 )included the following contents: (1) personal demographic factors; (2) the habit of visiting urban parks; (3) evaluation form, with 10 indices as shown in Table 1, for the semantic differential analysis. The interviewees were the users, not passers-by, and were selected randomly. The numbers of valid questionnaires in Donghu park and Nanhu park are 284 and 276. Demographic factors are also important for soundscape evaluation. Table 2 also shows the gender, age and education distribution of the interviewees in two parks. It can be seen that males were more than females, the $18-35$ and $35-55$

Table 1. Soundscape evaluation form

\begin{tabular}{|c|c|c|c|c|c|c|}
\hline & Very & Little & Neutral & Little & Very & \\
\hline Noisy & 2 & 1 & 0 & 1 & 2 & Quiet \\
\hline Gloomy & 2 & 1 & 0 & 1 & 2 & Sunny \\
\hline Unpleasant & 2 & 1 & 0 & 1 & 2 & Pleasant \\
\hline Cool & 2 & 1 & 0 & 1 & 2 & Warm \\
\hline Inactive & 2 & 1 & 0 & 1 & 2 & Active \\
\hline Oppressive & 2 & 1 & 0 & 1 & 2 & Open \\
\hline Indistinctive & 2 & 1 & 0 & 1 & 2 & Distinctive \\
\hline Artificial & 2 & 1 & 0 & 1 & 2 & Natural \\
\hline Dislike & 2 & 1 & 0 & 1 & 2 & Like \\
\hline Incongruous & 2 & 1 & 0 & 1 & 2 & Congruous \\
\hline
\end{tabular}


Table 2. Demographic profile of respondents

\begin{tabular}{|c|c|c|c|c|c|}
\hline \multicolumn{2}{|c|}{ Demographic variables } & \multirow{2}{*}{$\frac{\text { Donghu park }}{\text { - }}$} & \multirow{2}{*}{$\begin{array}{c}\text { Nanhu park } \\
41.1 \%\end{array}$} & \multirow{3}{*}{$\begin{array}{c}X^{2} \\
0.509\end{array}$} & \multirow{3}{*}{$\begin{array}{c}P \\
0.476\end{array}$} \\
\hline & Male & & & & \\
\hline S & Female & $53.6 \%$ & $58.9 \%$ & & \\
\hline \multirow{4}{*}{ Age } & $<18$ & $17.2 \%$ & $16.8 \%$ & \multirow{4}{*}{0.211} & \multirow{4}{*}{0.976} \\
\hline & $18-35$ & $33.6 \%$ & $33.2 \%$ & & \\
\hline & $35-55$ & $31.1 \%$ & $32.5 \%$ & & \\
\hline & $>55$ & $18.1 \%$ & $17.5 \%$ & & \\
\hline \multirow{3}{*}{ Education level } & Primary & $27.2 \%$ & $22.9 \%$ & \multirow{3}{*}{1.375} & \multirow{3}{*}{0.503} \\
\hline & Secondary & $29.4 \%$ & $31.4 \%$ & & \\
\hline & Higher level & $43.4 \%$ & $45.7 \%$ & & \\
\hline \multirow{4}{*}{$\begin{array}{c}\text { Frequency of coming } \\
\text { to the site }\end{array}$} & 1-2 times/day & $18.8 \%$ & $10.4 \%$ & \multirow{4}{*}{7.093} & \multirow{4}{*}{0.069} \\
\hline & 1-2 times/week & $42.3 \%$ & $38.6 \%$ & & \\
\hline & 1-2 times/month & $29.7 \%$ & $31.0 \%$ & & \\
\hline & 1-2 times/year & $9.2 \%$ & $20.0 \%$ & & \\
\hline
\end{tabular}

years old interewees respectively were about $30 \%$. And the educational level of the users was high, about $45 \%$ of the interviewees accepted higher education. About $50 \%$ of respondents visit the park weekly, but still $10 \%-20 \%$ respondents rarely go to the park. Chi-square test was conducted on data of respondents in two parks, and result showed that the crowd was representative.

\section{Results and Discussion}

3.1. Components and variation of the soundscape in the parks

From the on site investigations, the main components of soundscape have been identified as shown in Table 3. In the early morning, the sounds of birds and insects twittering, trees rustling, winds blowing, waters flowing and the sound of visitors gathering were the main elements of soundscape. In the morning, soundscape was gradually enriched, such as sounds of children, pedlar and entertainment facilities. At noon, social sounds would decrease because visitors decrease gradually. Soundscape in the afternoon was similar to that in the morning. In the evening, visitors' activities were at the peak, sound of entertainment facilities and gathering appearing in succession. Sound of transportation was almost heard in the parks each time, forming the background sound

Table 3. Main components of the Soundscape in the Parks

\begin{tabular}{llll}
\hline Time & Natural Sound & Social Sound & Artificial Sound \\
\hline \hline 6:00-8:00 & $\begin{array}{l}\text { water flowing, bird and insect } \\
\text { twittering, wind blowing, tree rustling }\end{array}$ & sound of people, sound of gathering & Sound of transportation \\
& water flowing, bird and insect twittering, & sound of people, sound of gathering, & sound of transportation, noise of \\
wind blowing, tree rustling, pet crying & sound of children, pedlar crying & facilities
\end{tabular}



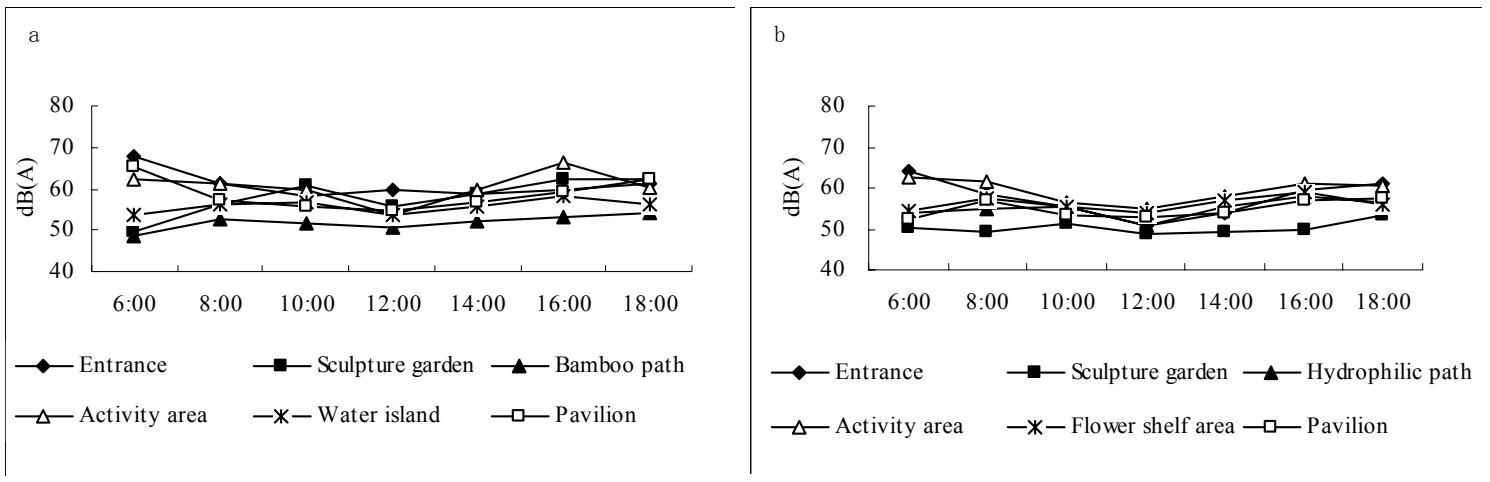

Fig. 1. Sound level in time distribution of every test point, Donghu park (a) and Nanhu park (b).

of the parks.

Fig. 1 showed sound level in time distribution of every test point. The noise value was lower in sculpture garden, bamboo path (hydrophilic path) and water island (flower shelf area), but other sites were interfered by noise in different degree. Sound level value of activity area from 6 am-8 am was higher, because of morning exercises. Sound level value was lower from $12 \mathrm{am}-14 \mathrm{am}$, and that of Nanhu park was lower by $55 \mathrm{~dB}$. The environment was noisy in $10 \mathrm{am}$ and $16 \mathrm{pm}$ with more visitors. Traffic noise made the park environment noisy at $18 \mathrm{pm}$ during rush hours.

\subsection{Semantic differential profiles of soundscape}

In terms of sound preference, people shared a common opinion in preferring natural sounds rather than artificial sounds (Qin and Sun, 2009; Lei and Jian, 2010). Water, birds, insects and breeze were most preferred sounds whereas traffic and construction noises were not popular. With the increase of age, people were more favorable to sounds relating to nature and human activities. But females and males were not significant in sound preference. Educational level was an influencing factor on sound preference, with the increase of educational level people tended to prefer natural sounds rather than mechanical sounds. In addition, activities also affected sounds preference. The sounds of people participating in singing, dancing and sports tended to be human activities sounds while that of people participating in walking, viewing and chatting were more like natural sounds.

In the questionnaire, we listed 10 pairs of subjective to let visitors express their impressions of soundscape in select points. The evaluations are shown in Table 4. Soundscape partition characteristics were the same in the two parks, both could be divided into 4 zones. The soundscape of the entrance area, the main entrance plaza, characterized by noisy, Indistinctive and artificial, was mainly composed of motor vehicle noise, street cries and broadcasting. The entertainment zone, the children activities area, fitness and entertainment district, characterized by active, pleasant and open, was mainly composed of children play sound, adults talk and music. The natural area, the waters and wildlife viewing area, characterized by natural, quiet and distinctive, was composed of sounds of birds, insects, waters, leaves and breeze. Feature of the leisure area, the main rest area, was not outstanding, but quiet, pleasant, warm and natural. Sounscape was composed of talking, natural sounds and other area incoming sound. In general, the Nanhu park evaluation value was higher than the Donghu park, because of different division and landscape design. The Nanhu park has a clear districts with a natural transition, and vegetation 
Table 4. The scores of soundscape in the two parks

\begin{tabular}{|c|c|c|c|c|c|c|}
\hline Indices (The Donghu park) & Entrance & $\begin{array}{c}\text { Sculpture } \\
\text { garden }\end{array}$ & Bamboo path & Activity area & Water island & Pavilion \\
\hline Noisy-Quiet & -1.01 & 1.39 & 1.07 & -1.27 & 0.96 & 0.78 \\
\hline Gloomy-Sunny & 0.46 & 0.78 & 0.48 & 0.61 & 0.53 & 0.56 \\
\hline Unpleasan-Pleasant & 0.32 & 0.93 & 0.59 & 1.18 & 0.86 & 0.48 \\
\hline Cool-Warm & 0.23 & 0.67 & -0.31 & 0.78 & -0.98 & 0.65 \\
\hline Inactive-Active & -0.15 & -0.50 & -0.24 & 1.30 & 0.54 & 0.38 \\
\hline Oppressive-Open & 0.31 & -0.80 & -0.78 & 0.91 & 0.35 & -0.27 \\
\hline Indistinctive-Distinctive & -0.25 & 1.10 & 1.21 & 0.82 & 1.05 & 0.36 \\
\hline Artifical-Natural & -0.83 & 0.93 & 1.09 & 0.34 & 0.86 & -1.23 \\
\hline Dislike-Like & 0.24 & 0.75 & 0.84 & 1.05 & 0.90 & 0.93 \\
\hline Incongruous-Congruous & 0.53 & 1.03 & 0.95 & 0.95 & 1.05 & 0.80 \\
\hline Noisy-Quiet & -0.92 & -0.50 & 0.86 & -1.20 & 0.85 & 0.68 \\
\hline Gloomy-Sunny & 0.52 & 0.26 & 0.48 & 0.60 & 0.53 & 0.96 \\
\hline Unpleasan-Pleasant & 0.32 & 0.85 & 0.86 & 1.05 & 0.56 & 0.75 \\
\hline Cool-Warm & 0.23 & -0.35 & -0.40 & 0.70 & 0.78 & 0.50 \\
\hline Inactive-Active & -0.21 & 0.56 & 0.76 & 1.23 & 0.54 & -0.23 \\
\hline Oppressive-Open & 0.31 & 0.78 & 0.84 & 0.93 & 0.35 & -0.25 \\
\hline Indistinctive-Distinctive & -0.25 & 0.89 & 1.12 & 0.75 & 0.78 & 1.20 \\
\hline Artifical-Natural & -0.86 & 0.53 & 1.23 & 0.45 & 0.86 & -1.05 \\
\hline Dislike-Like & 0.56 & 0.96 & 1.00 & 1.20 & 0.94 & 0.80 \\
\hline Incongruous-Congruous & 0.53 & 0.98 & 0.93 & 0.90 & 0.78 & 0.65 \\
\hline
\end{tabular}

resources more abundant, which can isolate sound propagation in the different regions.

\subsection{Semantic differential analysis}

Factor analysis (Berglund et al., 2001; Li and Chen, 2010 ) was made using all the data in the two parks. Varimax rotated principal component analysis was employed to extract the orthogonal factor underlying the 10 indices. With a criterion factor of eigenvalue $>1$, three factors were determined, as shown in Table 5. It can be seen that factor 1 $(41.75 \%)$ is mainly associated with relaxation, including noisy-quiet, unpleasant-pleasant, indistinctive -distinctive, artificial-natural, dislike-like, incongruouscongruous. Factor $2(26.86 \%)$ is mainly associated with spatiality, including inactive-active, oppressiveopen. Factor $3(17.26 \%)$ is mainly associated with environment, including gloomy-sunny, cool-warm.

Table 5. Factor analysis of the soundscape evaluation

\begin{tabular}{cccc}
\hline Indices & \multicolumn{3}{c}{ factors } \\
& $1(41.75 \%)$ & $2(26.86 \%)$ & $3(17.26 \%)$ \\
\hline \hline Noisy-Quiet & 0.102 & -0.319 & -0.065 \\
Gloomy-Sunny & 0.085 & -0.136 & 0.468 \\
Unpleasan-Pleasant & 0.223 & 0.095 & 0.165 \\
Cool-Warm & 0.007 & 0.082 & 0.484 \\
Inactive-Active & 0.110 & 0.292 & 0.042 \\
Oppressive-Open & 0.002 & 0.334 & -0.072 \\
Indistinctive-Distinctive & 0.233 & -0.146 & 0.043 \\
Artifical-Natural & 0.166 & -0.049 & -0.223 \\
Dislike-Like & 0.213 & 0.102 & 0.119 \\
Incongruous-Congruous & 0.215 & -0.050 & -0.110 \\
\hline
\end{tabular}


These three factors covered $85.87 \%$ of the total variance. These results could provide help for designers in actual work to consider the subjective feeling brought by soundscape and create a more suitable environment for people.

\section{Conclusion}

Urban park contains a lot of design components and plays an important role in the daily life of citizens. In this research, based on the soundscape, we performed several surveys in the two urban parks, and captured the components and structure of soundscape in urban parks as well as getting the evaluation of each component from visitors. The result showed that soundscape components and structure were related to functional partition and visitors' activities. The sound pressure level showed regular daily changes. We applied the semantic differential method to determine key factors, which can characterize the soundscape in urban parks. It was shown that the soundscape evaluation in urban parks was complicated, but it was still possible to identify the major factors, which include relaxation, spatiality and environment. Urban park design traditionally focused on visual sense design, the introduction of soundscape design will bring about the completion of design, appreciation and evaluation.

\section{References}

Bani, S., Paulo, H. T. Z., 2009, Analysis and evaluation of soundscapes in public through interviews and menasurement of noise, Science of Total Environment, 407, 6143-6149.

Berglund, B., Eriksen, C. A., Nilsson, M. E., 2001, Perceptual characterization of soundscapes in residential areas, In Proceedings of the 17th international congress on acoustics, Italy, Rome.
Chen, K. A., Lu, J., Yang, X. L., 2009, Experimental study on dimensionality of perceptual attributes for urban park soundscape, Noise and Vibration Control, 4, 132-137. (in Chinese).

Chinese National Standard, 2008, Emission standard for community noise, GB22337-2008. (in Chinese).

Ge, J., Kazunori, H., 2004, Research on the sound environment of urban open space from the viewpoint of soundscape-a case study of Saga forest park, Japan, Acta Acustica United With Acustica, 90, 555-563.

Ge, J., Lu, J., Guo, H. F., 2006, Research on structure of soundscape in urban open spaces and its design method, Journal of Zhejiang University (Engineering Science), 40, 9, 1569-1573. (in Chinese).

Kang, J., Zhang, M., 2010, Semantic differential analysis of the soundscape in urban open public spaces, Building and Environment, 45, 150-157.

Lei, Y., Jian, K., 2010, Factors influing the sound preference in urban open spaces, Applied Acoustics, 71, 622-633.

Li, X. S., Chen, Z. Z., 2010, Correctly using SPSS software for principal components analysis, Statistical Research, 27, 8, 105-108. (in Chinese).

Osgood, C. E., Suci, G. J., Tannenbaum, P. H., 1957, The measurement of meaning, Urbana, University of ILLINOIS Press.

Qin, H., Sun, C. H., 2009, Analysis of soundscape in urban park, Chinese Landscape Architecture, 7, 2831. (in Chinese).

Schafer, R. M., 1977, The tuning of the world, Alfred A Knopf, New York.

Zeitler, A., Hellbrück, J., 2001, Semantic attributes of environment sounds and their correlations with psychacoustic magnitudes, In Proceedings of the 17th international congress on acoustics, Italy, Rome.

Zhang, S., Ma, H., 2011, Analysis of sound environment in coastwise area of Haihe River and preliminary study on its soundscape design and expressin, Noise and Vibration Control, 3, 115-119. (in Chinese). 